\title{
Reconstrucción virtual del puente fortificado de la Media Luna (Cartagena de Indias) a través de herramientas digitales
}

Virtual reconstruction of the fortified bridge of the Media Luna (Cartagena de Indias) using digital tools

\author{
Karla Losada $^{\text {a }}$, Jorge Galindo-Díaz ${ }^{\text {b }}$, Joan Fontàs Serrat ${ }^{c}$ \\ ${ }^{a}$ Universidad Nacional de Colombia, Manizales, Colombia, kvlosadac@unal.edu.co \\ ${ }^{\mathrm{b}}$ Universidad Nacional de Colombia, Manizales, Colombia, jagalindod@unal.edu.co \\ ${ }^{\mathrm{c}}$ Universidad de Girona, Girona, Spain, joan.fontas@udg.edu
}

\begin{abstract}
One of the most important architectural pieces of the walled complex of Cartagena de Indias in Colombia was the so-called bridge of the Media Luna, whose first phase of construction dates back to 1628 . Since its construction, the Media Luna underwent several reforms and was submitted to some projects aimed at strengthening its defensive capacity conceived by military engineers at the service of the Spanish Crown, such as Juan Jiménez Donoso and Antonio de Arévalo. Despite this, a complete plan of the bridge, demolished at the end of the nineteenth century, has not been preserved, and it was never completely photographed. This paper, as a product of a research project related to the genesis of construction techniques in Cartagena de Indias, presents a digital reconstruction of the Media Luna after gathering and analyzing cartographic information still preserved in archives, photographs taken shortly before the demolition of the bridge, as well as traveler stories, descriptions and drawings done by nineteenth century chroniclers. The integral visualization of the Media Luna and its surroundings offers new value to the bridge and contributes to the integral understanding of the fortified complex of Cartagena de Indias.
\end{abstract}

Keywords: Fortified bridge, Cartagena de Indias, Antonio de Arévalo, Getsemaní.

\section{Introducción}

Buena parte del conjunto amurallado de Cartagena de Indias, máximo exponente de la arquitectura defensiva de los siglos XVII y XVIII en Colombia, ha sido víctima de un lento y desatendido proceso de destrucción y deterioro, en buena parte como resultado de la expansión urbana y el auge no controlado del turismo. A lo primero se le atribuye -entre otras cosas- la desaparición total de lo que fuera, para Zapatero (1979) y en palabras de Marco-Dorta (1960, p. 139) "la única entrada al recinto amurallado de Getsemaní, por la parte opuesta a la entrada a la ciudad". Este único acceso era el llamado "puen- te de la Media Luna", situado entre el pie del cerro donde se edificaría el castillo de San Felipe de Barajas y el arrabal de Getsemaní, en medio de las lagunas de San Lázaro y Chambacú.

El puente de la Media Luna llegó a ser en realidad parte de un complejo fortificado conocido como "la fortaleza de la Media Luna", el cual tuvo una destacada presencia en la vida diaria de los cartageneros: a nivel defensivo era el único punto de control para cualquier persona que se dirigía a la ciudad colonial desde tierra firme; desde el punto de vista urbano, era la conexión física entre la ciudad amurallada y su periferia 
agrícola y ganadera que, con el correr de los años, llegó a convertirse en hito y lugar de paso obligado para la población (Segovia, 2009).

Sin embargo, a pesar de su importancia, no se tiene en la actualidad certeza de su configuración espacial, pues solo quedan unos pocos registros planimétricos elaborados a lo largo de los siglos XVII y XVIII, así como algunas pinturas, relatos de cronistas y escasas fotografías tomadas en el último tercio del siglo XIX, que permiten, entre todos, apreciar el estado del puente desde sus orígenes hasta poco antes de su demolición, iniciada en 1884 y terminada en 1906.

Por su parte, estudios arqueológicos de finales del siglo XX llevados a cabo por Oyuela (1992) dan cuenta de que los vestigios materiales del puente colonial son prácticamente inexistentes, a excepción de la calzada del revellín, algunas estructuras de cimentación y buena parte de las paredes de los fosos de la tenaza, todos ellos sin embargo de difícil acceso para las personas.

$\mathrm{Y}$ es que con la llegada del siglo XX el aumento tanto de la población como del volumen de suministros que llegaban a la ciudad, hicieron que el puente fuese visto como un estorbo, puesto que, como lo expresan Urueta y Gutiérrez de Piñeres (1912, p. 92), su acceso era angosto, de tal manera que "en muchas ocasiones [personas y animales] se aglomeraban en uno de los dos extremos del túnel para esperar que les llegara el turno de pasar", a lo que se sumaba la falta de cuidado y mantenimiento que hacían ver la estructura en estado casi ruinoso, carente para entonces de todo valor defensivo (Redondo, 2004).

Esta comunicación describe el proceso de investigación histórica llevada a cabo a partir de los documentos antes mencionados con miras a la reconstrucción digital del complejo defensivo de la Media Luna, para así poder identificar de la manera más precisa posible su conformación espacial y sus características técnico-constructivas, permitiendo su puesta en valor y contribuyendo a la reconfiguración virtual del conjunto amurallado de Cartagena de Indias a lo largo del tiempo.

\section{Origen del puente de la Media Luna a tra- vés de fuentes cartográficas (siglos XVII y XVIII)}

Al término de la primera mitad del siglo XVI, Calamarí, el núcleo colonial de Cartagena de Indias, se encontraba aislado tanto de los islotes vecinos como de tierra firme; sin embargo, con el pasar los años y bajo una fuerte presión demográfica, indios, mestizos y libertos empezaron a residir en el islote de Getsemaní o Gimaní, fuera del recinto amurallado, a tal punto que para inicios del siglo XVII ya se levantaban allí casas de cantería junto a calles bien delineadas y se comercializaban diversos productos en plazas improvisadas (Díaz, Paniagua, 1993).

En 1621 se propuso la construcción de una muralla de mediana altura para proteger el arrabal y diez años más tarde se empezaron las obras en los baluartes de El Reducto y la Media Luna, este último, protegiendo el puente que unía Getsemaní con tierra firme, el mismo que para Oyuela (1992) y Ballestas (2008) era, en sus comienzos, solo una calzada que probablemente aprovechó para su construcción la existencia de una barra de arena estacada por sus dos lados que servía como vía destinada al pastoreo de las reses.

Con el constante tránsito la calzada se volvió un sendero de tierra apisonada que prolongaba la calle principal de Getsemaní hacia la base del cerro de San Lázaro. Así, para 1628 se contaba ya con el primer bosquejo de la estructura (Fig. 1), en donde se aprecia el baluarte de la Media Luna dotado de una puerta por la que se salía al puente, para luego atravesar un foso de agua corriente; la calzada se prolongaba hasta una tenaza dotada de muros bajos, o "media luna" que cubría la puerta con su artillería, junto a un segundo foso que precedía una nueva tenaza hasta terminar en un tercer foso de agua, antes de tocar tierra firme. En el interior del baluarte, dos rampas daban acceso a una plataforma elevada donde se disponían de 12 a 14 piezas de artillería.

Las tenazas, en la fortificación moderna, eran estructuras conformadas por un trozo de muralla (o "cortina") y dos semi baluartes, es decir, estructuras de planta angular destinadas a ejercer un 
mayor control visual sobre el espacio adyacente. En este caso, las tenazas daban forma a los bordes de la estructura sobre el agua y si bien poco contribuían a la movilización de las personas, carros y animales, sí posibilitaban la adecuada disposición de filas de cañones en actitud defensiva a la vez que permitían el dominio sobre el entorno inmediato.

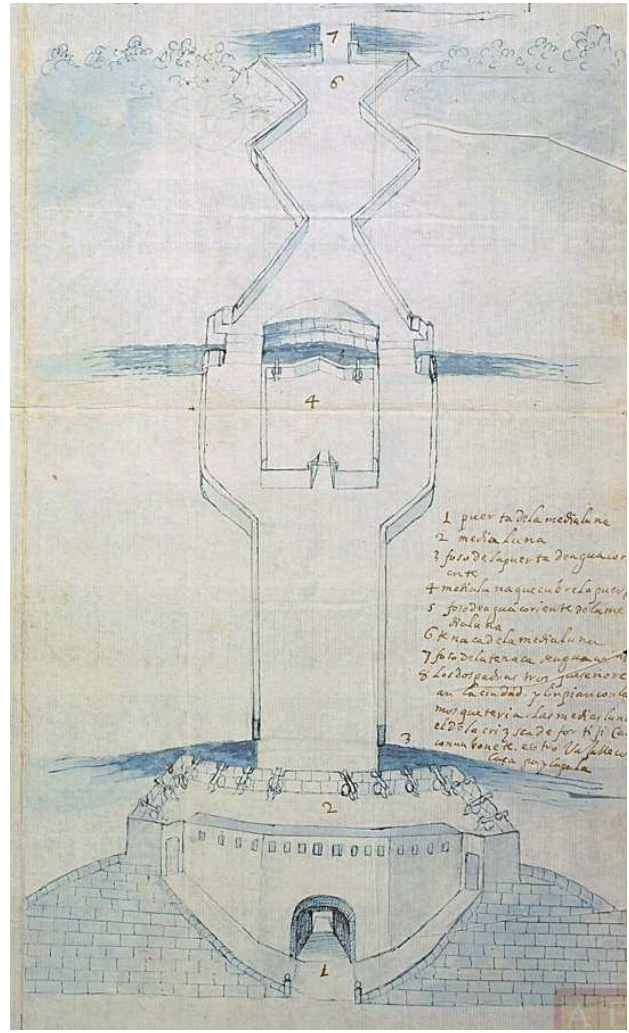

Fig. 1. Vista parcial del primer dibujo conocido del complejo de la Media Luna y defensas de la Puerta de la Plaza de Cartagena de Indias, 1628 (autor anónimo). Fuente: España, Ministerio de Cultura y Deportes. Archivo General de Indias. Panamá, 47.

No se tiene certeza acerca de si el puente, terminado en 1633, se completó siguiendo rigurosamente el diseño esbozado cinco años antes, pero sí se tiene noticia de su fracaso como obra de defensa cuando en 1697 el barón de Pointis atacó Cartagena de Indias concentrando sus acciones militares en el fuerte de Bocachica primero y en el de San Felipe después, desde donde atacó con cañones la entrada a la ciudad hasta destruir la
Media Luna, para finalmente hacer su ingreso al casco amurallado a través del arrabal de Getsemaní.

De los años siguientes datan varios proyectos de reparación y ampliación de la estructura. En 1730 se elaboró un proyecto a cargo de Juan de Herrera y Sotomayor, quien proponía la construcción de un "tenallón proyectado con su espaldón y puente levadizo para cerrar la entrada al baluarte de la Media Luna", así como la reparación del reducto situado en la mitad del puente; planteaba también la necesidad de hacer levadizos los otros puentes de madera sobre los fosos y dotar de "barreras" y "rastrillos" el punto de entrega del puente sobre tierra firme (Fig. 2).

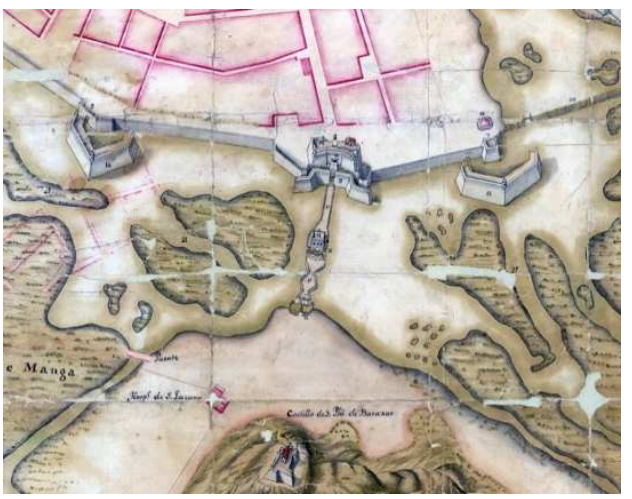

Fig. 2. Detalle del plano elaborado por Juan de Herrera y Sotomayor, 1730. Fuente: España. Ministerio de Defensa. Instituto de Historia y Cultura Militar. Archivo General Militar de Madrid, Sig. COL 09-10.

Entre 1754 y 1755 el ingeniero Lorenzo de Solís redactó otro proyecto más ambicioso consistente en la modificación del cuerpo principal del baluarte de la Media Luna reforzando su capacidad defensiva con dos semi baluartes, bautizados con los nombres de Santa Teresa y Santa Bárbara.

En este diseño (Fig. 3) se advierte una clara preocupación por ampliar el área útil para las piezas de artillería orientadas hacia las lagunas de San Lázaro y Chambacú, así como hacia la calzada del puente y la puerta principal, haciendo uso de orejones. Los cañones se ubicarían sobre una terraza que estaba construida sobre bóvedas de albañilería y que servía de cubierta a espacios utilitarios tales como almacenes, hospi- 


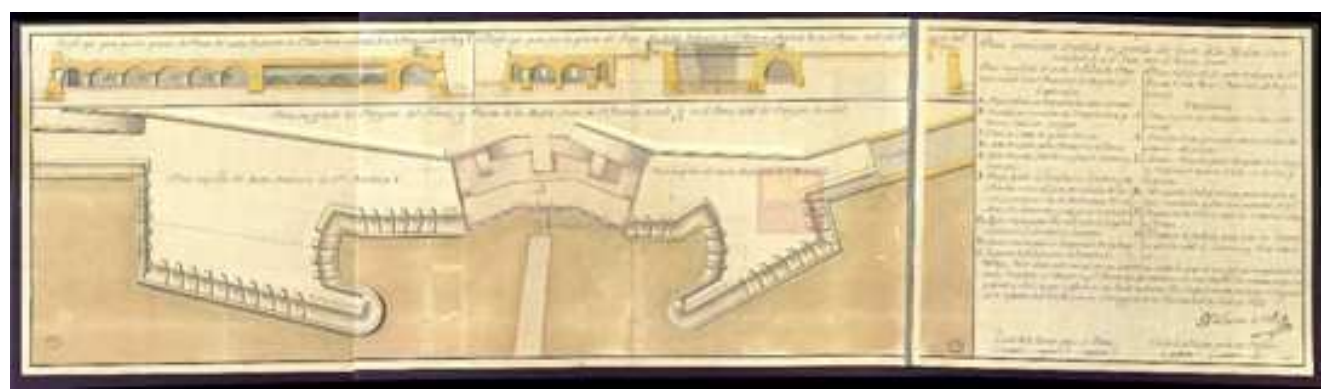

Fig. 3. Semibaluartes de Santa Teresa y Santa Bárbara diseñados por Lorenzo de Solís en 1755. Fuente: España, Ministerio de Cultura y Deportes. Archivo General de Indias. Panamá, 154.

tal, cocina, despensa y letrinas. El ingeniero Lorenzo de Solís también concibió la construcción del revellín de San Antonio, de traza más clásica (en forma de punta de lanza y con glacis) situado en la mitad del puente (que prácticamente reducía a la mitad su longitud), entre el baluarte y tierra firme, tal como lo recoge un plano firmado por Antonio de Arévalo y fechado en 1769 (Fig. 4); el revellín, sin embargo, nunca se construyó conforme a este diseño.

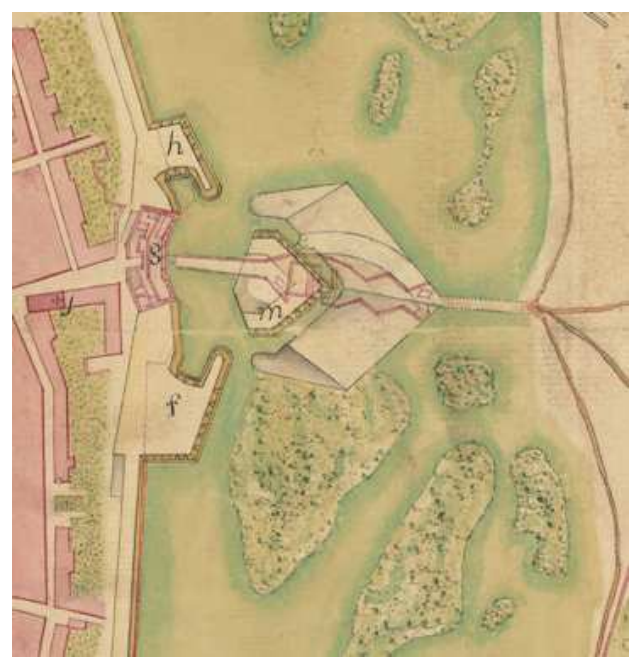

Fig. 4. Proyecto de un revellín en la mitad del puente, 1769. Fuente: España. Ministerio de Defensa. Instituto de Historia y Cultura Militar. Archivo General Militar de Madrid, Sig. COL 03-06.

Lo cierto es que Arévalo, durante sus años de labor en Cartagena de Indias, puso también su atención en el puente de la Media Luna: un plano de su autoría fechado 1780 da cuenta del estado general del puente en donde se aprecia una estructura casi idéntica a la que dejara concluida Lorenzo de Solís en 1755 (Fig. 5) y tres años más tarde él mismo proyectó una serie de obras destinadas a mejorar las condiciones de la puerta del baluarte optimizando sus condiciones de defensa (Fig. 6).

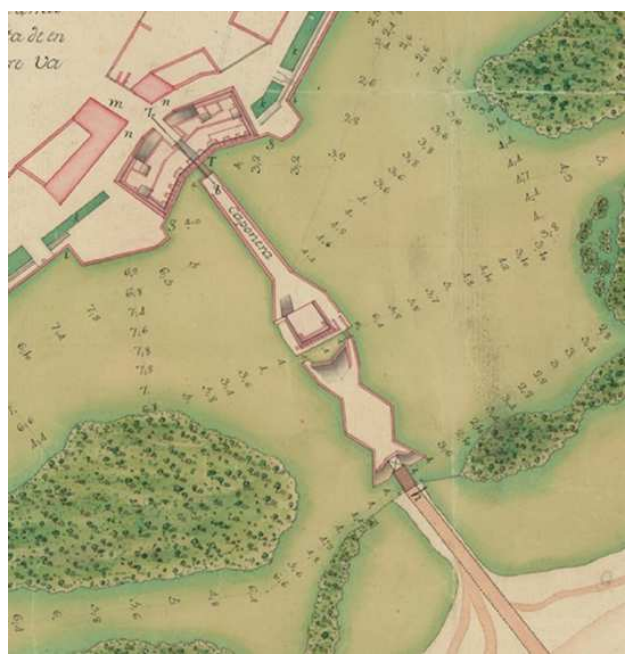

Fig. 5. Detalle del puente de la Media Luna, según Antonio de Arévalo, en 1780. Fuente: España. Ministerio de Defensa. Instituto de Historia y Cultura Militar. Archivo General Militar de Madrid, Sig. COL 08-01.

\section{Otras fuentes que revelan la imagen del puente de la Media Luna en las postrimerías del siglo XIX}

Durante buena parte del siglo XIX, durante el período de la República, el puente de la Media Luna se conservó íntegro pero desprovisto de su importancia estratégica y militar, tal como se aprecia en una acuarela realizada por Edward 
Walhouse Mark en 1843, en la cual el observador parece estar situado en la puerta misma del baluarte mirando hacia el castillo de San Felipe, que se distingue al fondo y sobre el cerro, dejando ver el reducto atravesado sobre la calzada; en él, tres arcos de descarga revelan la estructura de los muros portantes sobre los cuales se apoya una terraza a la cual se asciende por una rampa (Fig. 7).

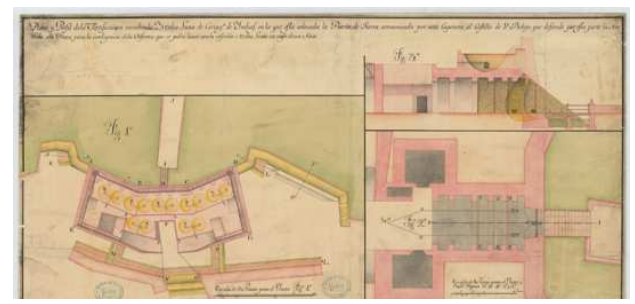

Fig. 6. Diseños para mejorar las condiciones del baluarte de la Media Luna, según Antonio de Arévalo, en 1783 (detalle). Fuente: España. Ministerio de Defensa. Instituto de Historia y Cultura Militar. Archivo General Militar de Madrid, Sig. COL 13-03.

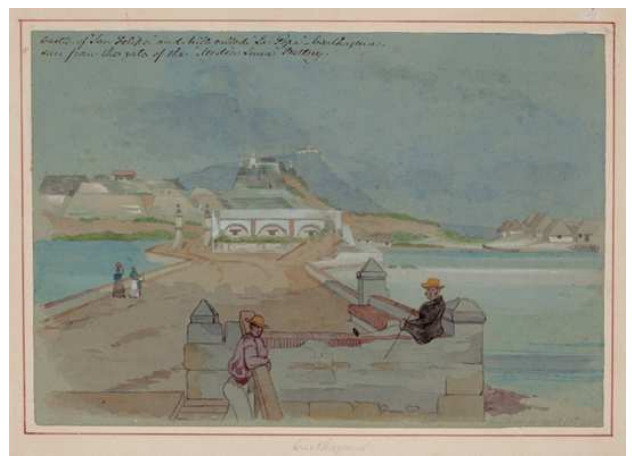

Fig. 7. Acuarela de Cartagena de Indias, por E.W. Mark, 1845. Fuente: Galería de Arte del Banco de la República de Colombia.

Casi idéntica es la fotografía de 1870 tomada como parte de la Darien Expedition del Comodoro Selfridges (Fig. 8), que permite reconocera diferencia de la pintura- las características de los materiales de las estructuras murarias y el pavimento de la calzada. Por su parte, una pintura anónima de esos mismos años, con el observador mirando en sentido contrario, es decir, desde el extremo de tierra firme hacia el baluarte, deja conocer la fachada del reducto (llamado entonces de manera equivocada "revellín"), el angosto puente de madera sobre el foso intermedio y al fondo, la puerta de entrada sobre la cortina (Fig. 9).

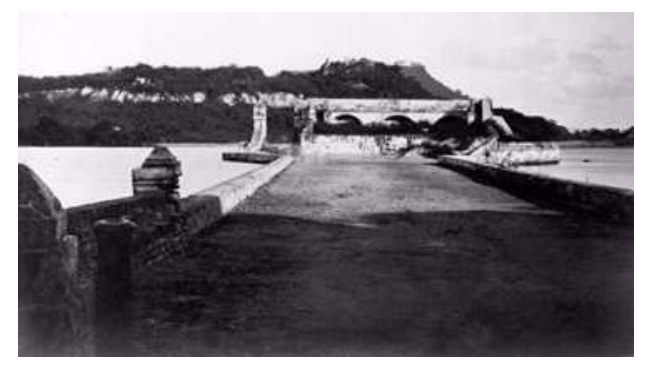

Fig. 8. Fotografía del puente de la Media Luna, por T. H. O’Sullivan. Cartagena, 1870. Colección Expedición Darién.

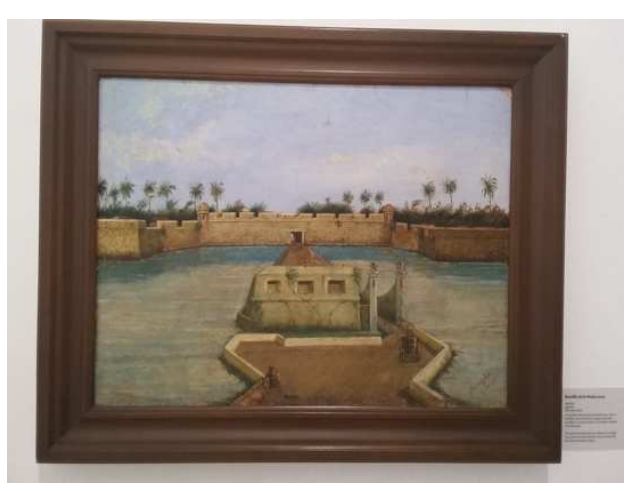

Figura 9. Revellín de la Media Luna. Pintura Anónima del siglo XIX. Fuente: Museo Histórico de Cartagena de Indias.

Considerado un estorbo para la movilización sobre el puente, el mal denominado "revellín" fue demolido mediante autorización contenida en la Ley 21 de 1883 (Oyuela, 1992) de tal manera que sus materiales pudieron ser reutilizados en la construcción de un nuevo puente o "ensanchamiento de la vía que allí existe". En efecto, una vez demolida la estructura se construyeron dos nuevos puentes en la zona media y se reubicaron las columnas que -rematadas con esferas de piedra- enmarcaban uno de los puentes levadizos de madera (Fig. 10).

En 1893 llegaría el turno de la demolición del baluarte de la Media Luna con el fin de ampliar la vía principal de Getsemaní y conformar un amplio relleno que se extendía desde la plata- 
forma del antiguo reducto hasta los semi baluartes de Santa Bárbara y Santa Teresa; adicionalmente se construyó un tercer puente en el medio lo que hizo más ancha el área de circulación.

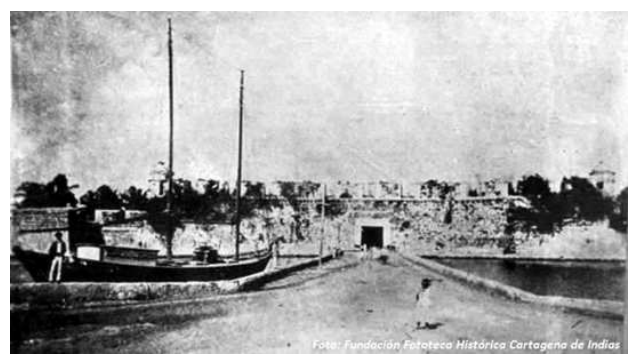

Fig. 10. Vista del puente de la Media Luna luego de la demolición del reducto, circa 1892. Fotografía de la fundación Fototeca Histórica Cartagena de Indias.

\section{Reconstrucción digital del puente de la Media Luna: principios y metodología}

Una vez identificado el valor del puente de la Media Luna en el devenir histórico de Cartagena de Indias y contando con la información planimétrica e iconográfica descrita, se procedió a elaborar un modelo digital tridimensional de la estructura.

Un primer paso consistió en la estimación de sus aspectos dimensionales a través del proceso de escalado a partir de las medidas legibles en los planos del siglo XVIII y considerando las equivalencias de unidades. La ausencia de secciones claras y suficientes dificultó este proceso, siendo necesario acudir a fotografías aéreas contemporáneas con el fin de sobreponer los planos antiguos con la estructura urbana actual y precisar la veracidad de la información.

Una vez se contó con una planta bidimensional, se exportó el archivo CAD al programa SketchUp, cuya interfaz de modelado es de mejor operatividad que el software 3ds-Max. En una primera fase se levantaron las volumetrías a partir de las imágenes y las pinturas de referencia y tratando de que el modelado fuese lo más fiel posible a sus registros, aunque en algunos casos no existiera coincidencia entre lo mostrado en la planimetría y lo plasmado en las fotografías.
Por último, se exportó el modelo obtenido a 3dsMax, programa que permitió caracterizar los materiales y sacar de allí imágenes puntuales que logran vistas del proyecto y dejan apreciar la volumetría de lo que se consideraba el complejo de la Media Luna (Figs. 11-16).

\section{Conclusiones}

En atención a las definiciones contenidas en los denominados Principios de Sevilla (LópezMenchero y Grande, 2011), el ejercicio desarrollado se inscribe en la categoría de reconstrucción virtual mediante la cual se intenta recuperar visualmente -a partir de un modelo virtual- la estructura del puente de la Media Luna en un momento determinado de su historia, a partir de las evidencias -documentales en este caso- y lo que de ellas se puede deducir, considerando además las prácticas constructivas y la tradición tipológica acorde con los principios de la fortificación moderna.

En este caso, el modelo virtual guarda un carácter sustitutivo del puente, en virtud de que sus vestigios materiales son prácticamente inexistentes. Su realización tiene fines divulgativos y educativos, apegándose a los principios de rigurosidad histórica, la cual se obtiene a partir de los planos y documentos que se consideran como fuentes.

En cuanto a las lecciones aprendidas a partir de la reconstrucción virtual del puente de la Media Luna, se advierte en su diseño la preocupación que tuvieron los ingenieros militares a su cargo por dar cumplimiento a los principios de la fortificación moderna en cuanto al ataque y la defensa de las plazas, bien difundidos en América a través de los tratados de fortificación.

Mientras que los puentes levadizos de madera situados en los extremos del puente y el reducto ubicado en el punto medio de la estructura hacen recordar algunos puentes fortificados medievales, la traza del baluarte en donde se sitúa la puerta principal, dotada de rampas y troneras, da respuesta adecuada a las condiciones impuestas por la artillería defensiva. 


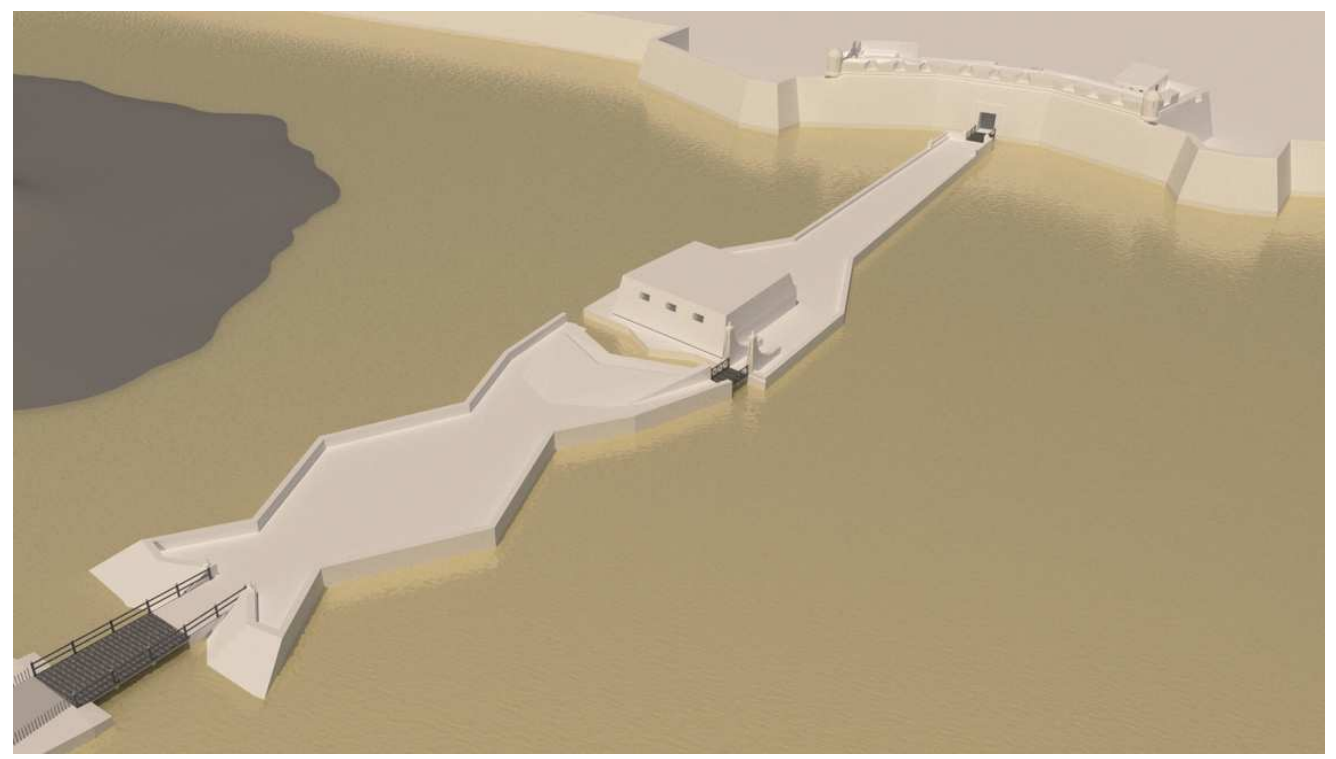

Fig. 11. Vista aérea del conjunto. (Autores).

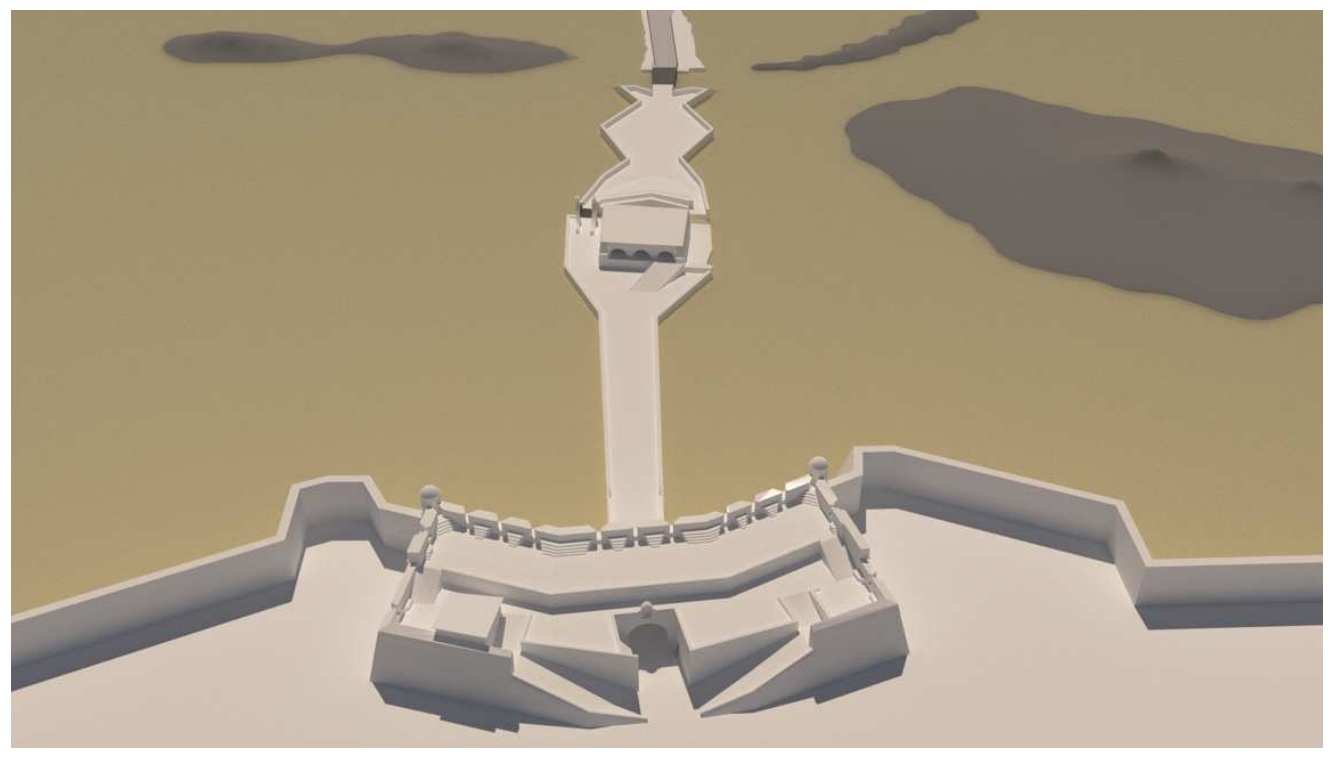

Fig. 12. Vista aérea del baluarte y puente de la Media Luna. (Autores). 


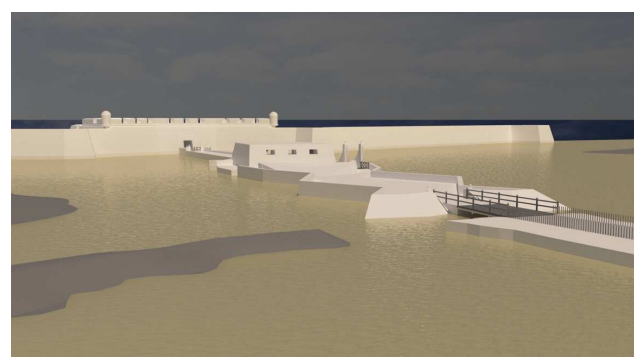

Fig. 13. Vista general desde tierra firme. (Autores).

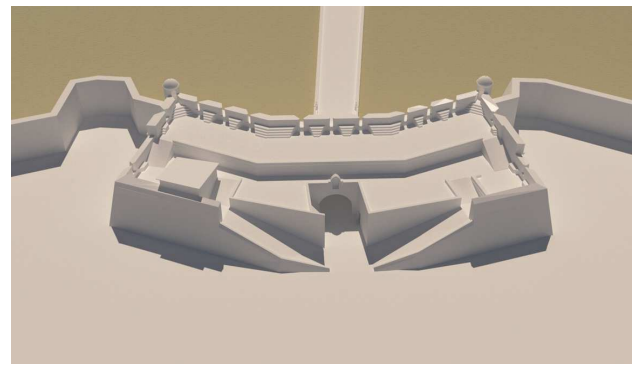

Fig. 14. Vista sobre el baluarte de la Media Luna. (Autores).

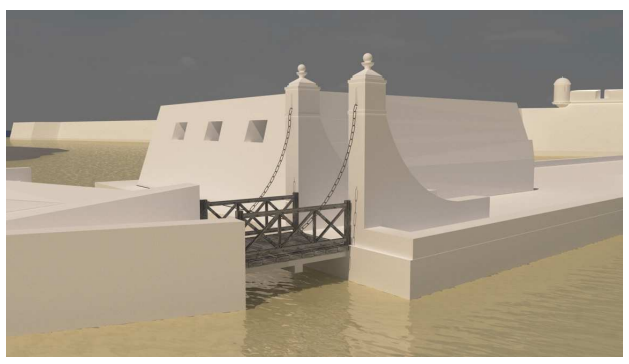

Fig. 15. Vista del puente de madera junto al reducto sobre el área media del puente de la Media Luna. (Autores).

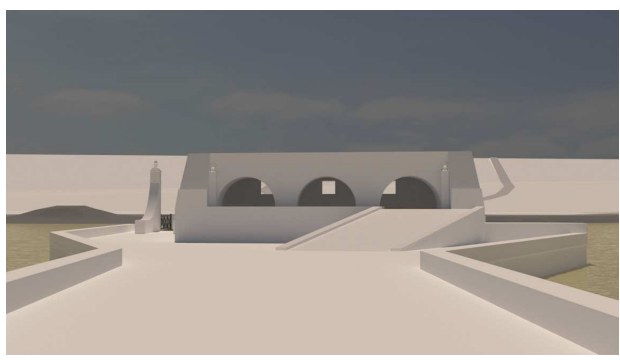

Fig. 16. Vista del reducto sobre el área media del puente de la Media Luna con el cerro de La Popa al fondo. (Autores).

\section{Bibliography}

Ballestas, R. (2008). Cartagena de Indias: relatos de la vida cotidiana y otras historias, Universidad Libre, Cartagena.

Díaz, R.A.; Paniagua, R. (1993). Getsemaní: Historia, patrimonio y bienestar social en Cartagena, Coreducar Ed., Cartagena.

López-Menchero, V.M.; Grande, A. (2011). "Hacia una carta internacional de arqueología virtual. El borrador SEAV", VAR, 2(4), pp. 71-75.

Marco-Dorta, E. (1960). Cartagena de Indias: Puerto y plaza fuerte, A. Amadó Ed., Cartagena.

Oyuela, A. (1992). Proyecto arqueológico "Puente Pedro de Heredia”, Edurbe, Cartagena de Indias, (inédito).

Redondo, M. (2004). Cartagena de Indias. Cinco siglos de evolución urbanística, Universidad Jorge Tadeo Lozano Ed., Bogotá.

Segovia, R. (2009). The Fortifications of Cartagena de Indias: Strategy and History, El Áncora Ed., Bogotá.

Urueta, J.; Gutiérrez de Piñeres, E. (1912). Cartagena y sus cercanías; guía descriptiva de la capital del Departamento de Bolívar, Tip. de Vapor Mogollón, Cartagena.

Zapatero, J. M. (1979). Historia de las fortificaciones de Cartagena de Indias, Cultura Hispánica, del Centro Iberoamericano de Cooperación Ed., Madrid. 